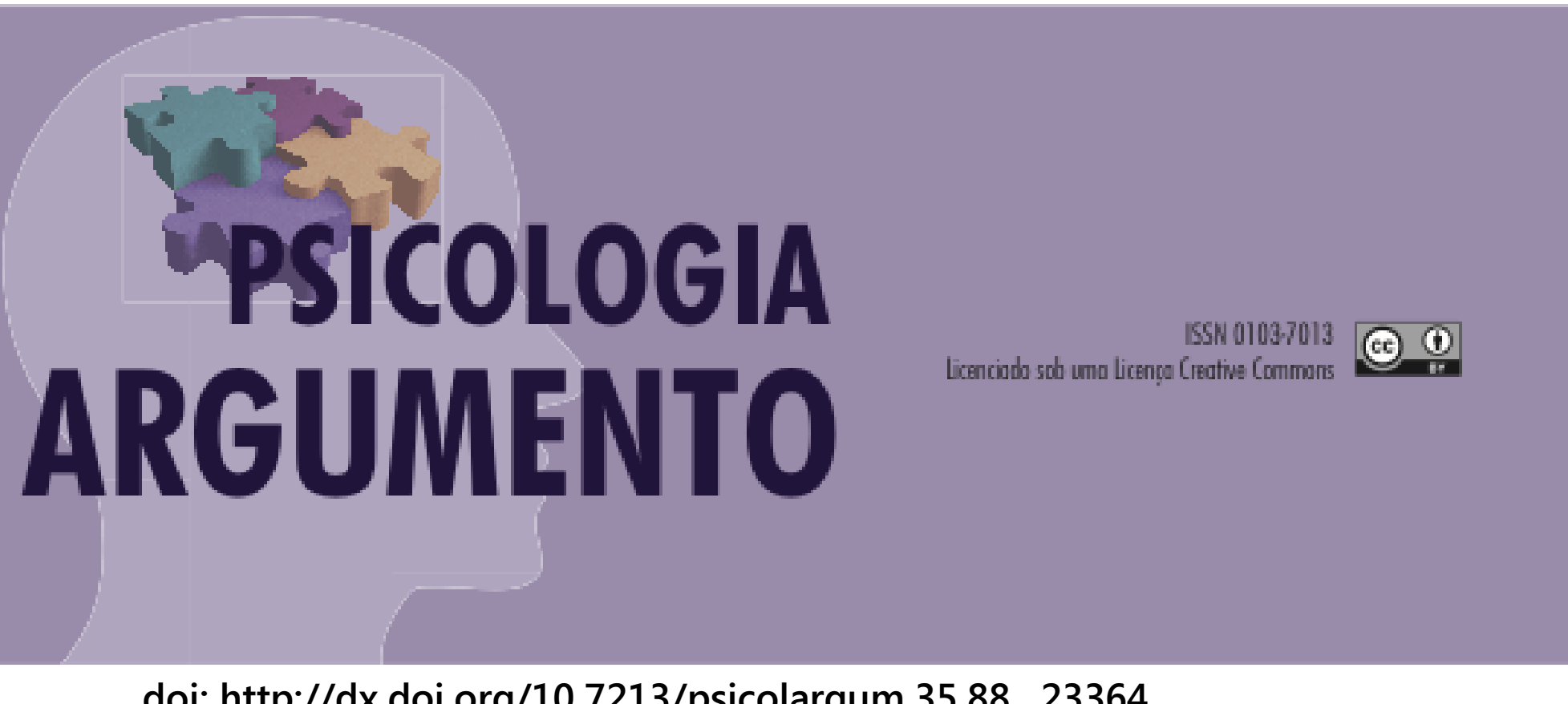

doi: http://dx.doi.org/10.7213/psicolargum.35.88. 23364

\title{
Relações de gênero e diversidade sexual na educação
}

\author{
Gender relations and sexual diversity in education
}

Eduardo Felipe Hennerich Pacheco[a], Sirley Terezinha Filipak[b].

[a] Mestre em Educação pelo Programa de Pós-Graduação em Educação da Pontifíicia Universidade Católica do Paraná (PUCPR), Curitiba, Paraná - Brasil, e-mail: eduardo.pva@hotmail.com.

[b] Doutora em Educação pelo Programa de Pós-graduação em Educação da Pontificia Universidade Católica do Paraná (PUCPR). Docente do Curso de

Pedagogia e do Programa de Pós-graduação em Educação (PUCPR), Curitiba, Paraná - Brasil, e-mail: sirley.filipak@pucpr.br

\begin{abstract}
Resumo
O presente artigo tem como foco principal do seu interesse discutir e analisar os mecanismos de exclusão que permeiam as relações de gênero e diversidade sexual na educação. Optou-se metodologicamente pela pesquisa documental e bibliográfica. A partir da escolha metodológica foi realizada uma discussão acerca do conceito de gênero como categoria histórica e social e o papel da educação na desconstrução de estereótipos e preconceitos que permeiam essas relações. Também se realizou um levantamento no banco de teses e dissertações da Coordenação de Aperfeiçoamento de Pessoal de Nível Superior (CAPES) para se verificar se essas temáticas estavam sendo comtempladas nas pesquisas de pós-graduação. As conclusões do estudo apontam que as instituições escolares são locais ambíguos. Ambíguos porque ao mesmo tempo em que podem construir e/ou reproduzir as hegemonias excludentes presentes na sociedade, elas podem transformá-las. E que apesar de se tratar de um tema complexo e de fundamental importância nosso mapeamento bibliográfico constatou que a problemática ainda é pouco pesquisada e trabalhada, o que de certo modo sugere que ainda as questões de identidade, sexualidade e relações de gênero são tratadas como tabus.
\end{abstract}

Palavras-chave: Relações de gênero, diversidade sexual, educação. 


\begin{abstract}
The main focus of this article is to discuss and analyze the mechanisms of exclusion that permeate gender relations and sexual diversity in education. Methodologically, the documentary and bibliographic research was chosen. From the methodological choice, a discussion was held about the concept of gender as a historical and social category and the role of education in the deconstruction of stereotypes and prejudices that permeate these relations. A survey was also carried out in the theses and dissertations bank of the Coordenação de Aperfeiçoamento de Pessoal de Nivel Superior (CAPES) to verify if these subjects were being contemplated in the postgraduate research. The findings of the study point out that school institutions are ambiguous places. Ambiguous because at the same time they can build and / or reproduce the exclusionary hegemonies present in society, they can transform them. And although it is a complex subject and of fundamental importance, our bibliographic mapping found that the problem is still little researched and worked, which in a way suggests that still the questions of identity, sexuality and gender relations are treated as taboos.
\end{abstract}

Keywords Gender relations, sexual diversity, education.

\title{
Introdução
}

No presente texto adotamos uma perspectiva crítica que compreende a sociedade como um território de conflitos e disputas de poder e a educação como uma atividade que possui uma natureza ambígua, que tanto pode construir e/ou reproduzir as hierarquias hegemônicas de normatividade e opressão como pode problematizar, indagar e transformar as estruturas dominantes.

Em tempos contemporâneos, líquidos e fluidos que "não fixam o espaço nem prendem o tempo" (Bauman, 2001, p. 8) se evidenciam as inúmeras possibilidades humanas de construção identitária. Movimentos sociais, feministas, LGBTTTI (Lésbicas, Gays, Bissexuais, Travestis, Transexuais, Transgêneros e Intersexuais), do campo, das águas, das florestas e étnico-raciais apoiados na emergência dos novos estudos culturais, de gênero e sexualidade, negros e identitário reivindicam, uma legítima, visibilidade social. Nesse processo de "afirmação e diferenciação, novas divisões sociais e o nascimento do que passou a ser conhecido como política de identidades" (Louro, 2000, p. 7) começou a fazer parte da agenda política brasileira, principalmente a partir da década de 1990.

Com a emergência das chamadas "políticas de identidades" (Louro, 2000; Hall, 1997) no campo político houve um considerado aumento, na produção intelectual, em temas ligados às questões da diversidade, identidade, diferença e desigualdades resultantes dos jogos de poder que essas marcações assinalam.

A partir desse contexto de emergência e visibilidade de questões antes ocultadas, pela hegemonia normativa, o presente artigo tem como interesse analisar os mecanismos de exclusão que permeiam as relações de gênero e da diversidade sexual na educação bem como analisar se essas problemáticas estão sendo contempladas nas teses e dissertações dos pesquisadores brasileiros.

O trabalho se organiza da seguinte maneira:

- primeiramente é abordado a metodologia trabalho, de caráter documental e bibliográfica; a justificativa e o detalhamento do estudo;

- na parte da discussão é desenvolvido uma análise de como o conceito de gênero passou a ser encarado como uma categoria útil para a análise histórica e social das relações humanas, e o papel da educação na construção identitária dos sujeitos tornando-se uma 
ferramenta ambígua que tanto pode reproduzir o contexto hegemônico da sociedade excludente da diferença, como pode transformá-lo;

- em seguida é apresentado os resultados e a análise do levantamento bibliográfico;

- nas considerações finais é destacado a pouca visibilidade - das problemáticas de gênero e diversidade sexual nas instituições escolares - nos trabalhos de teses de dissertações, e a importância de problematizar essas questões para a desconstrução de estereótipos e preconceitos.

\section{Metodologia}

A discussão da temática de gênero como análise histórica e social, bem como a relação de gênero com a educação e os mecanismos de exclusão e a fabricação de sujeitos teve como referência metodológica a pesquisa documental e bibliográfica referendada nos estudos de Guacira Louro (2001, 2012), Tomaz Tadeu da Silva (2001), Natalie Zemon Davis (1975), Maria Teresa Citeli (2001), Deborah Britzman (1996), Nilson Fernandes Dinis (2008), Michel Foucault $(1987,1996)$ entre outros autores.

A escolha metodológica da pesquisa documental e bibliográfica se deu em virtude de que se constitui em uma "preciosa fonte de informações" (Santos, 2000, p. 31), portanto, "[...] desenvolvida com base em material já elaborado, constituído principalmente de livros e artigos científicos" (Gil, 2002, p. 44).

Para Fonseca (2002) a pesquisa bibliográfica é realizada

[...] a partir do levantamento de referências teóricas já analisadas, e publicadas por meios escritos e eletrônicos, como livros, artigos científicos, páginas de web sites. Qualquer trabalho científico inicia-se com uma pesquisa bibliográfica, que permite ao pesquisador conhecer o que já se estudou sobre o assunto. Existem porém pesquisas científicas que se baseiam unicamente na pesquisa bibliográfica, procurando referências teóricas publicadas com o objetivo de recolher informações ou conhecimentos prévios sobre o problema a respeito do qual se procura a resposta (Fonseca, 2002, p. 32).

Já a pesquisa documental, é descrita por Pádua (1997, p. 62) como

[...] aquela realizada a partir de documentos, contemporâneos ou retrospectivos, considerados cientificamente autênticos (não fraudados); tem sido largamente utilizada nas ciências sociais, na investigação histórica, a fim de descrever/comparar fatos sociais, estabelecendo suas características ou tendências.

Deste modo, seguindo os mesmos caminhos da pesquisa bibliográfica, a pesquisa documental

[...] utiliza fontes constituídas por material já elaborado, constituído basicamente por livros e artigos científicos localizados em bibliotecas. A pesquisa documental recorre a fontes mais diversificadas e dispersas, sem tratamento analítico, tais como: tabelas estatísticas, jornais, revistas, relatórios, documentos oficiais, cartas, filmes, fotografias, pinturas, tapeçarias, relatórios de empresas, vídeos de programas de televisão, etc. (Fonseca, 2002, p. 32). 
Os dados do levantamento bibliográfico apresentados no trabalho foram coletados no banco de teses e dissertações da Coordenação de Aperfeiçoamento de Pessoal de Nível Superior (CAPES). A escolha específica desse banco de dados se deu por constituir-se no principal órgão oficial ligado ao Ministério da Educação (MEC), que reune os trabalhos dos pesquisadores brasileiros das principais Universidades do país.

Para realizar esse levantamento foram utilizadas as palavras-chave "relações de gênero nas escolas" e "diversidade sexual nas escolas" como descritores para localizar os estudos.

Na realização da pesquisa das produções foi priorizada a busca por todas as palavras dos descritores, bem como em todos os níveis stricto-sensu (mestrado e doutorado). Os critérios de inclusão dos trabalhos foram: serem pesquisas oriundas de programas de stricto sensu; corresponderem às pesquisas que investigassem as problemáticas de relações de gênero e diversidade sexual nas escolas e possuírem objetivos específicos da temática em seus resumos.

O levantamento foi realizado em vista de entendermos a relevância e a complexidade da temática e se ela estava sendo contemplada nos trabalhos de dissertações e teses dos pesquisadores brasileiros no período de 2000 a 2017.

\section{Discussão}

O conceito de gênero como categoria de análise histórica e social é algo recente na história da humanidade. Ele foi introduzido na literatura na década de 1970 pelos estudos e escritos dos grupos de feministas anglo-saxãs e estadunidenses. Para Joana Maria Pedro (2005, p. 78), “o uso da palavra gênero, [...], tem uma história que é tributária de movimentos sociais de mulheres, feministas, gays e lésbicas. Tem uma trajetória que acompanha a luta por direitos civis, direitos humanos, enfim, igualdade e respeito".

Em suas análises, esses estudos elaborados pelas feministas anglo-saxãs e estadunidenses ampliaram os conceitos de sexualidade e as representações sociais dos conceitos de masculinidades e feminilidade. Distanciando-se das compreensões biologizantes $^{1}$ e partindo de compreensões culturais evidenciaram que os conceitos de masculino e feminino estavam muito mais relacionados com questões culturais que biológicas (Scott, 1995).

O objetivo geral desses estudos e análises foi o desenvolvimento de uma teoria sobre a condição inferior das mulheres, gays e lésbicas na sociedade machista, heteronormativa e

\footnotetext{
${ }^{1}$ A socióloga Berenice Bento traz uma lista de autores que justificaram a dominação do patriarcado por meio de discursos médicos biológicos. Segundo a autora "há uma predominância de pesquisas que buscam encontrar causas hormonais (Bosinski et al., 1997; Mueller, et al., 2008); neuro-anatômicas (Luders et al., 2009; Garcia-Falgueras et al., 2008); preferência pela utilização da mão esquerda entre as pessoas trans (Green \& Young, 2001); dimensões das digitais (Green, \& Young, 2001; Elizabeth \& Green, 1984); herança genética (Bailey et al., 2000); peso inferior em relação aos irmãos não trans (Blanchard et al., 2002); pesquisa nos cariótipos (Inoubli et al., 2011); comportamentos autista inato (De Vries et al., 2010); elevadas taxas de síndrome dos ovários policísticos entre os homens trans (Balen et al., 1993); diferenciação sexual do cérebro (Blanchard, 2001); a influência dos hormônios sexuais na diferenciação sexual do cérebro dos mamíferos na fase pré-natal (Baba et al., 2007)" (Bento, 2016, p. 530-531). Todavia, segundo a autora essas teorias são inconclusivas e dispersas e não chegam a resultado algum.
} 
patriarcal (Louro, 2012). O termo gênero possibilitou uma relação analítica do vocabulário, introduzindo uma noção relacional entre os conceitos de masculino e de feminino, e não apenas evidenciando o feminino (Scott, 1995; Louro, 2012). A intelectual feminista Natalie Zemon Davis, em sua obra Women'sHistory in Transition: The European Case, assinala bem essa questão quando escreve que:

Penso que deveríamos nos interessar pela história tanto dos homens como das mulheres, e que não deveríamos tratar somente do sexo sujeitado, assim como um historiador de classe não pode fixar seu olhar apenas sobre os camponeses. Nosso objetivo maior é compreender a importância dos sexos, isto é, dos grupos de gênero no passado histórico. Nosso objetivo é descobrir o leque de papéis e de simbolismos sexuais nas diferentes sociedades e períodos, é encontrar qual é seu sentido e como eles funcionavam para manter a ordem social ou para mudá-la (Davis, 1975, p. 90).

Como observado por Davis, N. (1975), esse movimento empreendido pelas feministas mudou não apenas a história da mulher, mas também a história da compreensão das relações. Desmistificando a naturalização das características masculinas e femininas, os estudos sobre gênero defenderam que a construção do masculino e do feminino estavam muito mais ligados aos aspectos sociais e culturais do que biológicos e dessa maneira, esses estudos combateram

[...] o argumento de que homens e mulheres são biologicamente distintos e que a relação entre ambos decorre dessa distinção, que é complementar e na qual cada um deve desempenhar um papel determinado secularmente, acaba por ter o caráter de argumento final, irrecorrível. Seja no âmbito do senso comum, seja revestido por uma linguagem "científica", a distinção sexual serve para compreender - e justificar - a desigualdade social (Louro, 2012, p. 24-25).

Essa nova compreensão de gênero e de sexualidade, afastando-se da biologia - que insistia que era próprio do masculino as características de força, razão, astúcia e demais características hipervalorizadas e tidas como superiores e que o feminino, por sua vez, estava ligado a características emotivas, à maternidade, ao sensível e ao sentimental, ou seja, que sua natureza era biologicamente inferior ao homem (Louro, 2012) - e centrando-se nos aspectos sociais e culturais obrigou

[...] aquelas/es que o empregam a levar em consideração as distintas sociedades e os distintos momentos históricos de que estão tratando. Afasta-se de (ou se tem a intenção de afastar) proposições essencialistas sobre os gêneros; a ótica está dirigida para um processo, para uma construção, e não para algo que exista a priori. $\mathrm{O}$ conceito passa a exigir que se pense de modo plural, acentuando que os projetos e as representações sobre mulheres e homens são diversos. Observa-se que as concepções de gênero diferem não apenas entre as sociedades ou os momentos históricos, mas no interior de uma dada sociedade, ao se considerar os diversos grupos (étnicos, religiosos, raciais, de classe) que a constituem (Louro, 2012, p. 27). 
Como assinalado por Louro (2012), os estudos de gênero exigiram uma nova compreensão da realidade do ser masculino, do ser feminino e das hierarquias sociais que eles representavam. Para Citeli, M. (2001, p. 132)

[...] desnaturalizar hierarquias de poder baseadas em diferenças de sexo tem sido um dos eixos centrais dos estudos de gênero. Estabelecer a distinção entre os componentes - natural/biológico em relação a sexo e social/cultural em relação a gênero - foi, e continua sendo, um recurso utilizado pelos estudos de gênero para destacar essencialismos de toda ordem que há séculos sustentam argumentos biologizantes para desqualificar as mulheres, corporal, intelectual e moralmente.

Essa perspectiva assumida pelos estudos de gênero ajudou a melhor compreender o processo de construção social do masculino e do feminino, colocando o debate da sexualidade humana também no campo social, pois de acordo com Louro, G. (2012, p. 26)

[...] é nele que se constroem e se reproduzem as relações (desiguais) entre os sujeitos. As justificativas para as desigualdades precisariam ser buscadas não nas diferenças biológicas (se é que mesmo essas podem ser compreendidas fora de sua constituição social), mas sim nos arranjos sociais, na história, nas condições de acesso aos recursos da sociedade, nas formas de representação.

Dessa maneira, o conceito de gênero e as contribuições dos estudiosos da temática possibilitaram a compreensão da influência que a construção social exerce na determinação dos papeis de masculino e de feminino na sociedade, e ressalta a importância de assumirmos uma visão crítica, hermenêutica, histórica e cultural de como o conceito de gênero se delineou ao longo da história.

Nessa perspectiva, a educação desempenhou um papel na construção de estereótipos que ainda reforçam mecanismos de gênero na sociedade: lugares de meninos e lugares de meninas, esportes masculinos e esportes femininos, regras, linguagens adequadas.

\section{O papel da educação na construção das relações sociais}

As inúmeras possibilidades de construção identitárias colocam a educação em um território incerto e muitas vezes hostil quando elas são ignoradas e/ou omitidas. Diariamente, as escolas e universidades se deparam com uma gama de diversidade cultural, sexual, étnico-racial, religiosa, identitária, entre outras que adentram seus portões e, muitas vezes, não estão preparadas para acolher e incluir essa multiplicidade, excluindo-a.

Normalmente, essa exclusão é realizada por práticas, costumes, linguagens e mecanismos que segregam os sujeitos tidos como diferentes. Quando as instituições ignoram essa diversidade existente, elas não cumprem seu papel de formar integralmente os indivíduos para uma educação cidadã e libertária.

Bento (2008) aponta bem essa questão quando comenta que

[...] a escola, que se apresenta como uma instituição incapaz de lidar com a diferença e pluralidade, funciona como uma das principais instituições guardiãs das normas de gênero e produtora da heterosexualidade. Para os casos em que as crianças são levadas a deixar a escola por não suportarem o ambiente hostil é limitador 
falarmos em "evasão". No entanto, não existem indicadores para medir a homofobia de uma sociedade e, quando se fala na escola, tudo aparece sob o manto invisibilizante da evasão. Na verdade há um desejo em eliminar e excluir aqueles que contaminam o espaço escolar. Há um processo de expulsão e não de evasão (Bento, 2008, p. 129).

Um dos exemplos mais recentes dessa violência sofrida pelos estudantes que questionam a norma imposta socialmente é o comovente relato de Maria Clara Araújo, uma jovem de 18 anos, negra, travesti, discente do curso de Pedagogia na Universidade Federal de Pernambuco, que ao ser aprovada no vestibular escreveu um "manifesto pela igualdade sobre ser travesti e ter sido aprovada em uma universidade federal". No documento, Maria Clara Araújo relata sobre a violência velada que sofreu em sua vida de estudante desde a educação básica:

[...] se ontem a professora tirou a boneca de minha mão, hoje o Reitor diz não ter demanda para meu nome social. [...]. As violências por conta de minha identidade sempre trouxeram retaliações em salas, corredores e banheiros durante toda minha permanência na escola. Lembro-me de inúmeras vezes, minhas amigas entrando em rodas feitas por rapazes para me bater e tentarem me salvar. '’Para com isso! Deixa ela!'’[...]. Não era só comigo, mas fui a única que aguentei. $\mathrm{Vi}$, de pouco em pouco, outras possíveis travestis e transexuais desaparecendo daquele ambiente, porque ele nunca simbolizou um espaço de acolhimento, educação e aprendizagem. Mas sim de opressão, dor e rejeição (citado por Brito, 2016, p. 9).

A violência na educação básica e na educação superior sofrida por Maria Clara aparecem constantemente nas instituições de ensino. Portanto, ela não é uma experiência isolada.

Diariamente, alunos (as) e professores (as) vivenciam situações de constrangimentos e violências identitárias e de gênero, que, por serem invisibilizadas, demonstram aceitabilidade social.

Em um estudo elaborado pelo "Observatório de Violências nas Escolas", vinculado à cátedra da Organização das Nações Unidas para a Educação, a Ciência e a Cultura (UNESCO) de Juventude, Educação e Sociedade, do Programa de Pós-Graduação em Educação da Pontifícia Universidade Católica do Paraná (PUCPR) foram realizadas entrevistas individuais com alunos (as), professores (as) e pais/mães/responsáveis para observar em que medida os direitos fundamentais eram garantidos e/ou violados, e como resultado foi verificado que o principal direito a ser considerado como um direito fundamental a todo ser humano era o respeito. Para os participantes,

[...] diante da pergunta aberta "o que você considera como direito fundamental da pessoa?", as respostas evidenciam uma ampla constelação de direitos valorizados pelos participantes, os quais necessitam de proteção, pois ainda não estão suficientemente garantidos. Segundo posicionamentos dos estudantes, embora suas expectativas estejam distribuídas pelos diferentes direitos, o respeito é o mais importante (Eyng, 2015, p. 148). 
O respeito articulado com a igualdade, a cidadania e a participação figuram como os principais direitos a serem percebidos pela comunidade educacional (Eyng, 2015), e as instituições escolares representam um espaço político importante do exercício da liberdade. Por isso, elas têm o compromisso político de pensar as questões de gênero, sexualidade, orientação sexual e identidade para garantir que os Direitos Humanos, e, principalmente, o direito à identidade e à diferença seja assegurado e garantido.

Ferreira e Luz (2009, p. 37) relatam acerca do papel que a instituição escolar assume na fabricação e construção identitária dos sujeitos. Para as autoras “[...] o espaço escolar é um espaço relevante e que produz, reproduz, reafirma, desconstrói e legitima imagens e representações de gênero e sexualidade. Esse espaço é, no entanto, contraditório, pois, assim como pode reproduzir, pode também transformar."

Para elas, o espaço escolar é ambíguo e contraditório, pois, ao mesmo tempo ele pode acolher as diferenças de seus circundantes, sejam eles alunos, professores, funcionários ou até mesmo a comunidade que o cerca, ou adotar práticas omissas e mecanismos que garantam a invisibilidade desses sujeitos.

Essa invisibilidade apontada por Ferreira e Luz (2009), também é descrita pela pesquisadora Deborah Britzman (1996), que ao analisar a cultura escolar de "naturalidade" e "normalidade" de gênero e sexualidade comenta que

(...) a mera menção da homossexualidade vá encorajar práticas homossexuais e vá fazer com que os/as jovens se juntem às comunidades gays e lésbicas. A ideia é que as informações e as pessoas que as transmitem agem com a finalidade de "recrutar" jovens inocentes (...). Também faz parte desse complexo mito a ansiedade de que qualquer pessoa que ofereça representações gays e lésbicas em termos simpáticos será provavelmente acusada ou de ser gay ou de promover uma sexualidade fora-da-lei. Em ambos os casos, o conhecimento e as pessoas são considerados perigosos, predatórios e contagiosos (Britzman, 1996, p. 79-80).

Britzman, D. (1996) narra que o imaginário coletivo criado acerca da mera menção de assuntos como gênero, sexualidade e orientação sexual desperte uma mudança de orientação sexual dos estudantes.

Esse fato faz com que aqueles que não estejam no padrão imposto pela sociedade não sejam representados nas instituições escolares, que possuem currículos inflexíveis e práticas pedagógicas segregadoras. Os sujeitos transgressores passam a não existirem, uma vez que sua menção de sua existência causa pânico na "ordem" estabelecida.

Para Ferreira e Luz (2009, p. 36)

A forma como a sexualidade é percebida e vivida sofre interferência de uma conjunção de fatores, destacando as relações de poder e, particularmente, as de gênero. Essas, tradicionalmente, trazem em seu âmago construções de masculino e de feminino nas quais a sexualidade é vista, ensinada e controlada de formas distintas quando se trata de homens e mulheres.

Essa problemática, que envolve as relações de gênero e as relações de poder, já havia sido levantada pelo filósofo francês Michel Foucault. Em seus escritos ele observa que os

[...]mecanismos específicos de conhecimento e poder centrados no sexo se conjugam, desde o século XVIII, através de uma variedade 
de práticas sociais e técnicas de poder, produzindo discursos normativos sobre a sexualidade das mulheres e das crianças e classificando perversões sexuais, especialmente a homossexualidade (citado por Dinis, 2008, p. 482).

Foucault sinaliza que as instituições escolares se tornam um lugar de disputa de poder e de produção de hegemonias, que reproduzem aquilo que é imposto socialmente. As inúmeras práticas e discursos assumidos por elas tornam as subjetividades em objetos de classificação e exclusão.

As instituições devem ser o lócus da discussão sobre gênero e sexualidade, todavia, agressões físicas, psicológicas e de linguagem que permeiam essas relações estão presentes nas escolas, que não combatem esses tipos de violências.

De acordo com Ferreira e Luz (2009), essa indiferença das instituições e o silêncio a respeito das temáticas de gênero e sexualidade não é uma opção segura, ao contrário para as autoras

[...] a pedofilia, a violência sexual, a violência doméstica, a homofobia, o sexismo, o racismo, entre outras questões revelam que o silencio sobre o tema não representa possibilidades de se viver em uma sociedade que respeite as diferenças. O que tem imperado é o individualismo, a indiferença, o egoísmo, contribuindo para gerar relações que, em muitos casos, podem ser classificadas como patológicas e criminosas, como nos casos de abuso e de violência sexual e de gênero (Ferreira \& Luz, 2009, p. 40-41).

Essas questões não devem ser indiferentes tampouco silenciadas pelas instituições educacionais, pois elas fazem parte do cotidiano vivenciado pela comunidade escolar, não apenas pelos (as) alunos (as). Questões como a

[...] da identidade, da diferença e do outro é um problema pedagógico e curricular, especialmente, se o outro é o outro gênero, é a cor diferente, é a outra sexualidade, é a outra etnia, é a outra nacionalidade, é o corpo diferente. Problema maior ainda quando o outro não é aceito pela própria escola (Ferreira \& Luz, 2009, p. 41).

Essas problemáticas devem ser trabalhadas no currículo escolar para que a escola construa mecanismos que possibilitem uma convivência humana com respeito à alteridade por meio da dialogicidade.

\section{Mecanismos de exclusão e a fabricação de sujeitos}

Ao longo da história da educação inúmeros estereótipos foram construídos e ressignificados. O bom aluno e a boa aluna, o bom professor e a boa professora foram imagens e exemplos de normalidade a serem seguidas. Essas "imagens quebradas" (Arroyo, 2007) ainda produzem subjetivações de sujeitos e práticas que permeiam todos os setores das instituições escolares.

Observa-se que o fracasso escolar e a evasão dos sujeitos que não estão "adequados" à normatização aceita pelas instituições escolares estão intimamente relacionados a questões de discriminações, preconceitos e sentimentos de não pertença a esses estereótipos.

Foucault, M. (1987) pontua bem essa questão quando escreve que: 
o normal se estabelece como princípio de coerção no ensino, com a instauração de uma educação estandardizada e a criação das escolas normais; [...]. Tal como a vigilância e junto com ela, a regulamentação é um dos grandes instrumentos de poder no fim da era clássica. As marcas que significavam status, privilégios, filiações, tendem a ser substituídas ou pelo menos acrescidas de um conjunto de graus de normalidade, que são sinais de filiação a um corpo social homogêneo, mas que têm em si mesmos o papel de classificação, de hierarquização e de distribuição de lugares (Foucault, 1987, p. 153).

As escolas e universidades, de modo geral, não têm contemplado em seus currículos e práticas pedagógicas as multiplicidades das diferenças que permeiam suas instituições. Quando elas não contemplam essas diferenças esquecem que

[...] a educação e a escola são locais culturais estratégicos à reflexão e aos novos significados conferidos aos sujeitos e às práticas subordinadas [...] local de visibilidade, de voz e de ressignificação dessas identidades. [...] a multiplicidade das diferenças culturais (em especial a dos gêneros e das sexualidades), bem como o não reconhecimento pedagógico do caráter construído e político das identidades (hegemônicas e subordinadas) e de seus sujeitos. Além de esses temas estarem esquecidos, são frequentemente mal trabalhados, tanto pedagogicamente quanto nas relações sociais que se estabelecem na escola, a despeito das políticas educacionais que atualmente contemplam tanto a questão de gênero quanto à da sexualidade (Furlani, 2005, p. 225-226).

As práticas pedagógicas, os currículos ocultos e visíveis, as linguagens faladas ou não e os materiais didáticos, que são utilizados pelas instituições, promovem a fabricação dos sujeitos, reproduzindo e validando a hegemonia imposta socialmente.

Em "Vigiar e Punir" Michel Foucault escrevera que

A disciplina "fabrica" indivíduos: ela é a técnica específica de um poder que toma os indivíduos ao mesmo tempo como objetos e como instrumentos de seu exercício. Não é um poder triunfante [...]; é um poder modesto, desconfiado, que funciona a modo de uma economia calculada, mas permanente. Humildes modalidades, procedimentos menores, se os compararmos aos rituais majestosos da soberania ou aos grandes aparelhos de Estado (Foucault, 1987, p. 153).

Nessa relação, os sujeitos e as diferenças são excluídos, inclusive, aqueles que transgridem essa objetificação são extirpados lentamente do convívio social ou 
"patologizados" pelo discurso médico científico hegemônico ${ }^{2}$ e pelos dispositivos de poder ${ }^{3}$. Para Louro, G. (2012, p. 68), os

[...] currículos, normas, procedimentos de ensino, teorias, linguagem, materiais didáticos, processo de avaliação são, seguramente, loci das diferenças de gênero, sexualidade, etnia, classe - são constituídos por essas distinções e, ao mesmo tempo, seus produtores. Todas essas dimensões precisam, pois, ser colocadas em questão. É indispensável questionar não apenas o que ensinamos, mas o modo como ensinamos e que sentidos nossos/as alunos/as dão ao que aprendem.

A aplicação e escolha de determinados conteúdos não apenas demonstra o que Tomaz Tadeu da Silva (2001, p. 168) define como o "poder [...] inscrito no currículo" como também demonstra que a escolha do que é considerado conhecimento ou não, está intimamente relacionado com a produção e fabricação de sujeitos e das suas "identidades étnicas, de gênero, de classe" (Louro, 2012, p. 89).

A construção identitária e o processo de "fabricação" dos sujeitos não é algo evidente, ao contrário, os mecanismos e práticas utilizadas nessa construção são sutis e discretos. Louro, G. (2012) exemplifica esse ponto quando traz à tona que

[...] antes de tentar percebê-lo pela leitura das leis ou dos decretos que instalam e regulam as instituições ou percebê-lo nos solenes discursos das autoridades (embora todas essas instâncias também façam sentido), nosso olhar deve se voltar especialmente para as práticas cotidianas em que se envolvem todos os sujeitos. São, pois, as práticas rotineiras e comuns, os gestos e as palavras banalizados que precisam se tornar alvos de atenção renovada, de questionamento e, em especial, de desconfiança. A tarefa mais urgente talvez seja exatamente essa: desconfiar do que é tomado como "natural" (Louro, 2012, p. 67).

\footnotetext{
${ }^{2}$ A ciência como detentora do conhecimento, toma para si a responsabilidade de criar e discutir os assuntos (conhecimentos) que antes pertencia a esfera do Estado e da igreja e: "passa a dissecar o sexo do homem, da mulher, da criança, do adulto, do normal e do anormal. Acontece aí a emersão do que Foucault chama de scientiasexualis, desenvolvida pela burguesia a partir do século XIX para a produção sobre a verdade do sexo. Com esta scientiasexualis o Estado burguês toma para si as rédeas da vida humana, entendida como um corpo vivo inserido num organismo vivo" (Prestes \&Vianna, 2008, p. 318).

${ }^{3} \mathrm{O}$ conceito de dispositivo procura demarcar: "um conjunto decididamente heterogêneo que engloba discursos, instituições, organizações arquitetônicas, decisões regulamentares, leis, medidas administrativas, enunciados científicos, proposições filosóficas, morais, filantrópicas. Em suma, o dito e o não dito são os elementos do dispositivo. 'O dispositivo é a rede que se pode estabelecer entre estes elementos. Em segundo lugar, gostaria de demarcar a natureza da relação que pode existir entre estes elementos heterogêneos. Sendo assim, tal discurso pode aparecer como programa de uma instituição ou, ao contrário, como elemento que permite justificar e mascarar uma prática que permanece muda; pode ainda funcionar como reinterpretação desta prática, dando-lhe acesso a um novo campo de racionalidade. Em suma, entre estes elementos, discursivos ou não, existe um tipo de jogo, ou seja, mudanças de posição, modificações de funções, que também podem ser muito diferentes. Em terceiro lugar, entendo dispositivo como um tipo de formação que, em um determinado momento histórico, teve como função principal responder a uma urgência. O dispositivo tem, portanto, uma função estratégica dominante" (Foucault, 1979, p. 244).
} 
A "naturalidade" mencionada por Louro, G. (2012) é constantemente assegurada pelas práticas cotidianas que ocultam o "diferente" e hegemoniza as relações sociais. Seguramente, o campo mais promissor e eficaz dessa instância normatizadora é a linguagem, "tanto porque ela atravessa e constitui a maioria de nossas práticas, como porque ela nos parece, quase sempre, muito 'natural"” (Louro, 2012, p. 69).

Muito mais que natural, para Denise Portinari $(1989$, p. 18) a linguagem "é um turbilhão e nos usa muito mais do que nós a usamos. Ela nos carrega. Molda, fixa, modifica, esmaga (seria talvez a depressão: sou esmagada pela palavra) e ressuscita (não há a "palavra de salvação"?)".

A efetividade da linguagem é tal que ela "institui e demarca os lugares dos gêneros não apenas pelo ocultamento" do diferente, do feminino, do homossexual, do transexual e do "outro", "e sim, também, pelas diferenciadas adjetivações que são atribuídas aos sujeitos, pelo uso (ou não) do diminutivo, pela escolha dos verbos, pelas associações e pelas analogias feitas entre determinadas qualidades, atributos ou comportamentos" (Louro, 2012, p. 71).

As instituições educacionais exercem um papel primordial na garantia da vigilância e do controle das normatizações sociais porque "a escola entende disso. Na verdade, a escola produz isso. Desde seus inícios, a instituição escolar exerceu uma ação distintiva. Ela se incumbiu de separar os sujeitos" (Louro, 2012, p. 61). E essa participação que a educação assume na separação, regulação, submissão e produção de sujeitos dóceis às estratégias do poder, é muito claro no pensamento de Foucault. Para o autor " [...] a penalidade, a vigilância e o controle seriam então uma maneira de gerir as ilegalidades, de riscar limites de tolerância, de dar terreno a alguns, de fazer pressão sobre outros, de excluir uma parte, de tornar útil outra, de neutralizar estes, de tirar proveito daqueles" (Foucault, 1987, p. 230).

Essa construção de espaços que as instituições escolares criam e delimitam são construtos signatários que "afirmam o que cada um pode (ou não pode) fazer" (Louro, 2012, p. 62). Esses espaços ambíguos proporcionados pela educação

[...] pode muito bem ser, de direito, o instrumento graças ao qual todo indivíduo, numa sociedade como a nossa, pode ter acesso a qualquer tipo de discurso; sabemos, no entanto, que, na sua distribuição, naquilo que permite e naquilo que impede, ela segue as linhas que são marcadas pelas distâncias, pelas oposições e pelas lutas sociais. Todo sistema de educação é uma maneira política de manter ou de modificar a apropriação dos discursos, com os saberes e poderes que estes trazem consigo (Foucault, 1996, p. 45).

Os discursos assumidos pelas instituições escolares demarcam a posição hegemônica que eles reproduzem e informa aos circunscritos desse sistema seu devido lugar. Não sem sentido que a divisão é a parte estruturante das instituições escolares. Divisões em turmas, séries, etapas, créditos, disciplinas escolares, lugares de meninos e de meninas, espaços permitidos e proibidos. E aqueles que não se adaptam à performance signatária das instituições são postos às margens do sistema e lentamente expurgados. Quando são levianamente "tolerados", o são na perspectiva das relações de poder. Silva, T. (2001, p. 88) esclarece essa questão quando sugere que 
Apesar de seu impulso aparentemente generoso, a ideia de tolerância, por exemplo, implica também uma certa superioridade por parte de quem mostra 'tolerância'. [...] do ponto de vista mais crítico, as diferenças estão sendo constantemente produzidas e reproduzidas através de relações de poder. As diferenças não devem ser simplesmente [...] toleradas. Na medida em que elas estão sendo constantemente feitas e refeitas, o que se deve focalizar são precisamente as relações de poder que presidem sua produção.

A própria tolerância como mencionada por Silva (2001), torna-se mecanismo de objetificação dos sujeitos. Essa objetivação ocorre quando ressignificam-se essas práticas, que até então apareciam em níveis abstratos e muitas vezes ocultadas, em situações concretas.

Para o psicólogo social Serge Moscovici (2003, p. 71) "a objetivação une a ideia de não-familiaridade com a de realidade, torna-se a verdadeira essência da realidade", e assim, transplanta "para o nível da observação o que era apenas inferência ou símbolo" (Moscovici, 1978, p. 111). Desse modo, até quando são toleradas as diferenças (sexuais, de gênero, de identidade) tornam-se objetos de exclusão e marginalização. Isso ocorre porque a tolerância envolve um movimento ambíguo de quem tolera. Ambíguo porque ela não aceita e nem reprova as práticas do outro e aquele que tolera cinge a fronteira da diferença, sempre sinalizando que a igualdade não é possível entre aqueles que toleram e os que são tolerados. Além disso, como sugere Silvia Duschatzky e Carlos Skliar (2000, p. 175)

A tolerância, assinala, emerge como palavra suave, nos exime de tomar posições e de responsabilizarmo-nos por elas. A tolerância debilita as diferenças discursivas e mascara as desigualdades. Quanto mais polarizado se apresenta o mundo e mais prolifera todo tipo de bunkers, mais ressoa o discurso da tolerância e mais se toleram formas inumanas de vida [...]. A tolerância consagra a ruptura de toda contaminação e revalida os guetos, ignorando os mecanismos através dos quais foram construídos historicamente. A tolerância não põe em questão um modelo social de exclusão, quando muito trata de ampliar as regras de urbanidade com a recomendação de tolerar o que aparece como molesto. A tolerância tem um forte ar familiar com a indiferença. Corre o risco de tomarse mecanismo de esquecimento e levar seus portadores a eliminar de uma só vez as memórias da dor.

Cabe ressaltar que as inúmeras possibilidades identitárias do ser humano são asseguradas pela Lei de Diretrizes e Bases da Educação Nacional (LDBEN), n. ${ }^{\circ} 9.394$ aprovada em 1996, que estabelece a garantia de acesso e permanência na educação de todos e quaisquer sujeitos independentemente de suas diferenças e igualdades (Brasil, 1996).

Dessa maneira, a educação deve tornar-se o meio para a concretização da liberdade de ser de cada um e deve impedir quaisquer formas de discriminação em relação à gênero, classe, etnia, diversidade cultural, religiosa, filosófica, política, entre outras questões, que impedem a convivência harmoniosa na sociedade.

\section{Resultados do levantamento da produção científica}

A partir da década de 1990 as questões de identidade, gênero, diferença e diversidade passaram a fazer parte de uma forma mais intensa das pesquisas brasileiras e como objeto 
das políticas públicas educacionais. Alinhado a um discurso internacional de multiculturalismo - basta evocar o relatório para a UNESCO da Comissão Internacional sobre Educação para o século XXI (Delors, 1996) - as inúmeras possibilidades de diferenças culturais e diversidades se tornaram objetos de incessantes desdobramentos intelectuais.

Todavia, a pretensa visibilidade desses assuntos os transformou em uma "uma armadilha conceitual e uma estratégia política de esvaziamento e/ou apaziguamento das diferenças e das desigualdades" (Rodrigues \& Abramowicz, 2013, p. 17). Além disso, essas indagações intelectuais pouco promoveram mudanças concretas na realidade educacional brasileira. Os currículos e práticas pedagógicas ainda preservam uma estrutura arcaica e medieval.

Se os conceitos de relações de gênero e diversidade sexual caíram no modismo midiático, as análises realizadas sobre a produção acadêmica científica brasileira revelam que esses conceitos ainda são tímidos em vista da complexidade da temática.

Ao analisarmos o levantamento da produção científica sobre a problemática em questão, para registrar o que vem sendo pesquisado e escrito pelos pesquisadores brasileiros, constatamos que as temáticas em epígrafe ainda não são visíveis.

Utilizando o termo "DIVERSIDADE SEXUAL NAS ESCOLAS" (em maiúscula e entre aspas, para obter resultados precisos) no período de 2000 a 2017, foram encontrados quatro resultados que podem ser observados no quadro 1 .

Quadro 1: Pesquisa com o termo "diversidade sexual nas escolas"

\begin{tabular}{|c|c|c|}
\hline Autor/Titulação & Título & Objetivos \\
\hline $\begin{array}{l}\text { SANTOS, Marcia Cunha } \\
\text { Dos. } \\
\text { 14/03/2014 } 254 \mathrm{f} \text {. } \\
\text { Mestrado em Ensino e } \\
\text { História das Ciências e da } \\
\text { Matemática. }\end{array}$ & $\begin{array}{l}\text { Os discursos de gênero } \\
\text { e diversidade sexual } \\
\text { nas escolas estaduais da } \\
\text { região de Mogi das } \\
\text { Cruzes (SP). }\end{array}$ & $\begin{array}{l}\text { Identificar os discursos sobre gênero e } \\
\text { diversidade sexual que perpassam os } \\
\text { projetos de educação para a sexualidade } \\
\text { nas escolas da região. }\end{array}$ \\
\hline $\begin{array}{ll}\text { SANTOS, } & \text { Lauren } \\
\text { Aparecida De } & \text { Souza. } \\
\text { 30/03/2015 89 f. } & \\
\text { Mestrado em Educação. }\end{array}$ & $\begin{array}{l}\text { Alteridade } \quad \text { na } \\
\text { educação: o sentir o si e } \\
\text { o outro }\end{array}$ & $\begin{array}{l}\text { Realizar uma revisão bibliográfica de } \\
\text { temas relacionados com a diversidade, } \\
\text { alteridade, diferença e sexualidade na } \\
\text { educação, com foco nos teóricos } \\
\text { franceses contemporâneos: Gilles } \\
\text { Deleuze, Félix Guattari e Michel } \\
\text { Foucault. }\end{array}$ \\
\hline $\begin{array}{l}\text { MANSUR, Maria Elisabete } \\
\text { do Valle. } \\
\text { 19/05/2014 } 213 \text { f. } \\
\text { Mestrado em educação. }\end{array}$ & $\begin{array}{lll}\text { Diversidade } & \text { sexual em } \\
\text { escolas } & \text { públicas } \\
\text { estaduais do rio } & \text { de } \\
\text { janeiro: vozes } & \text { de } \\
\text { professores (as). } & \end{array}$ & $\begin{array}{l}\text { Investigar a diversidade sexual no } \\
\text { espaço escolar, a partir das vozes dos } \\
\text { professores de ensino médio de escolas } \\
\text { públicas do Rio de Janeiro. }\end{array}$ \\
\hline $\begin{array}{l}\text { VIEIRA, Hamilton Edio } \\
\text { dos Santos. } \\
\text { 26/08/2014 } 168 \mathrm{f} \text {. } \\
\text { Mestrado em Educação } \\
\text { Escolar. }\end{array}$ & $\begin{array}{l}\text { A Construção Dos } \\
\text { Saberes Docentes: um } \\
\text { olhar sobre as } \\
\text { experiências } \\
\text { professores de } \\
\text { disciplina de História } \\
\text { acerca da temática de } \\
\text { diversidade sexual. }\end{array}$ & $\begin{array}{l}\text { Investigar as questões sobre a prática } \\
\text { docente em relação a seus saberes } \\
\text { acionados diante de resolver demandas e } \\
\text { necessidades quando a diversidade } \\
\text { sexual emergia no cotidiano escolar. }\end{array}$ \\
\hline
\end{tabular}

Fonte: autores (2017).

Como observado no quadro 1, utilizando a expressão "DIVERSIDADE SEXUAL NAS ESCOLAS" foram encontradas quatro dissertações apresentadas em programas de mestrados em educação e somente um deles apresenta o pensamento dos professores em relação à temática. Há necessidade de ouvir não somente professores, mas alunos, 
funcionários, famílias e toda a comunidade escolar. Por meio do diálogo, da troca de experiências, da discussão, as instituições escolares podem minimizar o preconceito existente.

Por sua vez, o termo "RELAÇÕES DE GÊNERO NAS ESCOLAS" contou com dois resultados encontrados no período de 2004 a 2015. Esses dados podem ser analisados no quadro 2 .

Quadro 2 - pesquisa com o termo "Relações de Gênero nas Escolas"

\begin{tabular}{|c|c|c|}
\hline Autor/Titulação & Título & Objetivos \\
\hline $\begin{array}{l}\text { GUERRA, Oldênia } \\
\text { Fonseca. 01/12/2004 } 150 \text { f. } \\
\text { Mestrado em Educação. }\end{array}$ & $\begin{array}{l}\text { Relações de Gênero nas } \\
\text { Escolas Agrotécnicas } \\
\text { Federais do Piauí: entre } \\
\text { diferenças } \\
\text { preconceitos. }\end{array}$ & $\begin{array}{l}\text { Tem como objetivo analisar } \\
\text { como são tecidas as relações no } \\
\text { gênero no ensino agrícola } \\
\text { piauiense, } \\
\text { especialmente marcado pela } \\
\text { hegemonia masculina. }\end{array}$ \\
\hline $\begin{array}{l}\text { VEDOVATO, } \\
\text { Marina Milhassi. } \\
\text { 31/08/2015 } 205 \mathrm{f} \text {. } \\
\text { Mestrado em Educação e } \\
\text { Saúde Na Infância E } \\
\text { Adolescência }\end{array}$ & $\begin{array}{l}\text { Um olhar sobre a } \\
\text { violência sexual nas } \\
\text { práticas educativas } \\
\text { escolares: prevenção da } \\
\text { violência de gênero e da } \\
\text { violação do corpo } \\
\text { feminino. }\end{array}$ & $\begin{array}{l}\text { Objetivou estudar e avaliar } \\
\text { ações educativas com } \\
\text { adolescentes em âmbito escolar, } \\
\text { com foco na prevenção da } \\
\text { violência de gênero e suas } \\
\text { consequências na violação do } \\
\text { corpo feminino. }\end{array}$ \\
\hline
\end{tabular}

Observa-se que no levantamento elaborado (quadros 1 e 2), o número de estudos acerca das problemáticas da diversidade sexual e das relações de gênero nas escolas ainda é reduzido. A partir da análise do material pesquisado percebem-se as seguintes características:

a) a maioria das dissertações retratam estudos de casos;

b) a prática pedagógica e o papel do(a) professor(a) são objetos da maioria dos trabalhos;

c) o período de maior concentração dos estudos é de 2014 e 2015, com exceção de uma pesquisa elaborada em 2004;

d) a região Sudeste do Brasil conta com a maior parte das análises acerca da diversidade sexual nas escolas e das relações de gênero que permeiam as instituições escolares.

\section{Considerações finais}

O levantamento realizado possibilitou a compreensão que as temáticas investigadas ainda não fazem parte dos núcleos estruturantes dos programas de pós-graduação stricto sensu no Brasil. E, além disso, ele revela o quão recente é o interesse em levar essa discussão para a produção de pesquisas que auxiliam na desconstrução de estereótipos ligados a relações de gênero, identidade e sexualidade na educação.

O problema que orientou essa discussão consistiu em analisar os mecanismos de exclusão que permeiam as relações de gênero e diversidade sexual na educação, bem como identificar se essas temáticas estavam sendo comtempladas nos trabalhos dos pesquisadores brasileiros. 
Nos resultados encontrados percebemos que mesmo em se tratando de uma temática extremamente necessária à produção de teses e dissertações ainda é limitada e muito se tem a avançar.

Na discussão, procuramos evidenciar o papel da educação na construção identitária dos sujeitos e quais os mecanismos de exclusão reproduzidos ou criados pelas instituições escolares, e como eles permeiam as relações de gênero e sexualidade promovendo e reproduzindo os estereótipos hegemônicos da sociedade.

Em nosso percurso analítico, concluímos que as instituições escolares são locais ambíguos porque ao mesmo tempo em que podem reproduzir hegemonias presentes na sociedade as instituições podem transformá-las. Apesar de se tratar de um tema complexo e de fundamental importância, nosso mapeamento bibliográfico constatou que a problemática ainda é pouco pesquisada e trabalhada, o que de certo modo sugere que as questões de identidade, sexualidade e relações de gênero são tratadas como tabus.

As práticas de exclusão da diversidade identificadas no presente trabalho operam não apenas em conjuntos explícitos de códigos negativos e excludentes de interdições e censuras como também se efetivam nos discursos, práticas, ideias, conhecimentos que definem e regulam aquilo que é permitido, distinguindo o legítimo do ilegítimo, o dizível do indizível (Junqueira, 2009).

Além disso, em sintonia com o Plano Nacional de Educação aprovado em 2014 que estabelece na meta 3 "universalizar, até 2016, o atendimento escolar para toda a população de quinze a dezessete anos e elevar, até o final do período de vigência deste PNE, a taxa líquida de matrículas no ensino médio para oitenta e cinco por cento", e para o cumprimento desta, sugere na estratégia 3.13, "implementar políticas de prevenção à evasão motivada por preconceito ou quaisquer formas de discriminação, criando rede de proteção contra formas associadas de exclusão" (BRASIL, 2014), há necessidade de ampliar os conhecimentos acerca da problemática de gênero e diversidade sexual e de promover o diálogo com todos e encontrar as possíveis alternativas para conter a evasão.

Entender que as problemáticas de identidade, relações de gênero e sexualidade devem ser incluídas nas teses e dissertações dos pesquisadores brasileiros e nos currículos e práticas pedagógicas das instituições escolares significa entender que esses conhecimentos são essenciais para a promoção da igualdade para a construção de uma sociedade mais justa, equânime e democrática.

\section{Referências}

Arroyo, M. G. (2007). Imagens quebradas: trajetórias e tempos de aluno se mestres. Petrópolis: Vozes.

Bauman, Z. (2001). Modernidade Líquida. Rio de Janeiro: Zahar.

Bento, B. A. (2008). 0 que é transexualidade. São Paulo: Brasiliense.

Bento, B. A. (2016). Disforia de gênero: geopolítica de uma categoria psiquiátrica. Revista Direito E PráXis, 7(3), 496-536.

Brasil, Ministério da Educação. (1996). Lei de Diretrizes e Bases da Educação Nacional. Estabelece as diretrizes e bases da educação nacional. Diário Oficial da União. Brasília: 
DF. Disponível em: http://www.planalto.gov.br/ccivil_03/leis/L9394.htm. Acesso em 29 out.

Brasil, (2014). Plano Nacional de Educação 2014-2024: Lei no 13.005, de 25 de junho de

2014, que aprova o Plano Nacional de Educação (PNE) e dá outras providências. Brasília: Câmara dos Deputados, Edições Câmara, 2014. 86 p. - (Série legislação ; n. 125). Disponívelem:http://www.observatoriodopne.org.br/uploads/reference/file/439docum ento-referencia.pdf. Acesso em 29 out.

Brito, C. P. (2016). “Já é negro e ainda quer ser travesti?" - Experiencias trans de mulheres negras. Dissertação de mestrado, Universidade Estadual do Sudoeste da Bahia, Jequié, BA, Brasil.

Britzman, D. (jan/jul de 1996). 0 que é essa coisa chamada amor - Identidade homossexual, educação e currículo. Educação e Realidade.

Citeli, M. T. (2001). Fazendo a diferenças: teorias sobre gênero, corpo e comportamento. Rev. Estud. Fem., 131-145.

Davis, N. Z. (1975). Womens's History in Transition: The European Case.Feminist Studies.

DELORS, J. (1996). Educação: um tesouro a descobrir. Relatório para a UNESCO da Comissão Internacional sobre Educação para o século XXI. 3. ed. São Paulo: Cortez; Brasília: MEC/UNESCO.

Dinis, N. F. (maio/agosto de 2008). Educação, relações de gênero e diversidade sexual. Educação \& Sociedade, pp. 477-492.

Duschatzky, S.; Skliar, C. (jul/dez de 2000). Os nomes dos outros. Reflexões sobre os usos escolares da diversidade. Educação e Realidade, 25(n.2), pp. 163-178.

Eyng, A. M. (2015). Currículo e avaliação: duas faces da mesma moeda na garantia do direito à educação de qualidade social. Revista Diálogo Educacional, 15(44), 133-155.

Ferreria, B. M., \& Luz, N. S. (2009). Sexualidade e gênero na escola. Em N. S. Luz, M. G. Carvalho, \& L. Salete, Construindo a igualdade na diversidade: gênero e sexualidade na escola (pp. 33-46). Curitiba: Ed. UTFPR.

Fonseca, J. J. (2002). Metodologia da pesquisa científica. Fortaleza: UEC.

Foucault, M. (1987). Vigiar e Punir. Petrópolis: Vozes.

Foucault, M. (1996). A ordem do discurso: aula inaugural no Collège de France. São Paulo: Edições Loyola.

Foucault, M. (1979). Microfísica do poder. Rio de Janeiro: Graal.

Furlani, J. (2005). Gêneros e Sexualidades: políticas identirárias na educação sexual. Em M. P. Grossi, S. Becker, \& J. C. Losso, Movimentos Sociais, Educação e Sexualidade (p. 278). Rio de Janeiro: Garamond.

Gil, A. C. (2002). Como elaboras projetos de pesquisa. São Paulo: Atlas. 
Guerra, O. F. (2004). Relações de gênero nas escolas agrotécnicas federais do Piauí: entre diferenças e preconceitos. Dissertação de mestrado, Universidade Federal do Piauí, Teresina, PI, Brasil.

Hall, S. (1997). Identidades culturais na pós-modernidade. Rio de Janeiro: DP\&A.

Junqueira, R. D. (2009). Homofobia nas escolas: um problema de todos. Em R. D. Junqueira, Diversidade sexual na educação: problematizações sobre a homofobia nas escolas (pp. 13-51). Brasília: MEC/UNESCO.

Louro, G. L. (2012). Gênero, sexualidade e educação: uma perspectiva pós-estruturalista. Petrópolis: Vozes.

Louro, G. L. (2000). Pedagogias da sexualidade. Em G. L. Louro (org.), O Corpo Educado (pp. 07-34). Belo Horizonte: Autêntica Editora.

Mansur, M. E. V. (2014). Diversidade Sexual em Escolas Públicas Estaduais do Rio De Janeiro: Vozes de Professores (As). Dissertação de mestrado, Universidade Federal do Estado do Rio de Janeiro, Rio de Janeiro, RJ, Brasil.

Moscovici, S. (1978). A representação Social da Psicanálise. Rio de Janeiro: Zahar Editores.

Moscovici, S. (2003). Representações Sociais: investigação em psicologia social. Petrópolis: Vozes.

Pádua, E. M. (1997). Metodologia da pesquisa: abordagem teórico-prática. São Paulo: Papirus.

Pedro, J. M. (2005). Traduzindo o debate: o uso da categoria gênero na pesquisa histórica. História (São Paulo), 24(1), 77-98.

Portinari, D. (1989). 0 discurso da homossexualidade feminina. São Paulo: Brasiliense.

Pretes, É. A. \& Vianna, T. (2008). "História da criminalização da homossexualidade no Brasil: da sodomia ao homossexualismo". In: LOBATO, Wolney; SABINO, Cláudia \& ABREU, João Francisco (orgs.). Iniciação Científica: destaques 2007 Vol. I. Belo Horizonte: Ed. PUC Minas. p. 313-392.

Rodrigues, T. C., \& Abramowicz, A. (2013). 0 debate contemporâneo sobre a diversidade e a diferença nas políticas e pesquisas em educação. Educação e Pesquisa, 39(1), 15-30.

Santos, A. R. (2000). Metodologia científica: a construção do conhecimento. Rio de Janeiro: DP\&A.

Santos, M. C. (2014). Os Discursos De Gênero E Diversidade Sexual Nas Escolas Estaduais Da Região De Mogi Das Cruzes (SP). Dissertação de mestrado, Universidade Federal do Abc, Santo André, SP, Brasil.

Santos, L. A. S. (2015). Alteridade na Educação: O sentir o si e o outro. Dissertação de mestrado, Universidade Federal de São Carlos, São Carlos, SP, Brasil.

Scott, J. W. (1995). Gênero: uma categoria útil para análise histórica. In: Educação \& Realidade. Porto Alegre, vol. 20, no 2, jul./dez. pp. 71-99, Recuperado em 28 de setembro 
https://edisciplinas.usp.br/pluginfile.php/185058/mod_resource/content/2/G\%C3 \%AAneroJoan\%20Scott.pdf>

Silva, T. T. (2001). Documentos de identidade: uma introdução às teorias do currículo. Belo Horizonte: Autêntica.

Vedovato, M. M. (2015). Um olhar sobre a violência sexual nas práticas educativas escolares: Prevenção da violência de gênero e da violação do corpo feminino. Dissertação de Mestrado, Universidade Federal de São Paulo, SP, Brasil.

Vieira, H. E. S. (2014). A Construção Dos Saberes Docentes: um olhar sobre as experiências de professores da disciplina de História acerca da temática de diversidade sexual. Dissertação de mestrado, Universidade Est. Paulista Júlio De Mesquita Filho, Araraquara, SP, Brasil.

Recebido em: 28/05/2017

Aprovado em: 21/09/2017 